\title{
COMPOSIÇÃo gUÍMICA DA CACHAÇA PRODUZIDA NA REGIÃo NOROESTE DO RIO GRANDE DO SUL, BRASIL ${ }^{1}$
}

\author{
Stanislau BOGUSZ JUNIOR ${ }^{2, *}$, Daiane Cristina Mertins KETZER ${ }^{3}$, \\ Raquel GUBERT ${ }^{3}$, Lucieli ANDRADES ${ }^{3}$, Anagilda Bacarin GOBO ${ }^{4}$
}

\begin{abstract}
RESUMO
Com o objetivo de conhecer a composição química e os requisitos de qualidade da cachaça produzida na Região Noroeste do Estado do Rio Grande do Sul, foram analisadas 27 amostras de cachaça, produzidas e comercializadas em 18 municípios pertencentes às microrregiões Ijuí, Cruz Alta, Santa Rosa e Três Passos, que integram o Noroeste do Rio Grande do Sul, Brasil, e compararam-se os valores encontrados com aqueles estabelecidos pela Legislação. Para as análises estatísticas, aplicaram-se os testes de ANOVA e Tukey. As amostras avaliadas apresentaram valores médios de teor alcoólico, acidez, álcoois superiores, aldeídos, ésteres e metanol dentro do que estabelece a Legislação. Entretanto os valores de intervalo de concentração para estes mesmos parâmetros revelaram amostras fora do estipulado por Lei, indicando falta de conhecimento tecnológico de produção por parte de alguns dos produtores. Sugere-se a ampliação do presente estudo, com a finalidade de se investigar outros aspectos tecnológicos, tendo em vista a otimização dos processos de fabricação e a melhoria da qualidade da bebida.

Palavras-chave: cachaça, qualidade, composição química, destilados.
\end{abstract}

\section{SUMMARY}

CHEMICAL COMPOSITION OF THE SUGAR CANE SPIRIT "CACHAÇA” PRODUCED IN THE NORTHWEST AREA OF RIO GRANDE DO SUL, BRAZIL. With the aim of knowing the chemical composition and quality requirement of the sugar cane spirit, "cachaça" produced in the Northwest Region of the Rio Grande do Sul State, 27 samples of "cachaça" were analyzed, produced and marketed in 18 municipal districts that belong to the areas of Ijuí, Cruz Alta, Santa Rosa and Três Passos, which are in the Northwest of Rio Grande do Sul State, Brazil. The values found were compared with the ones established in the Legislation. Concerning the statistical analyses, the ANOVA and Tukey tests were applied. The evaluated samples showed a medium value of alcoholic text, acidity, higher alcohols, aldehydes, esters and methanol within what the Legislation establishes. However, the interval values of concentration to these same parameters revealed samples that are not stipulated by law, showing a lack of technological knowledge of production by some of the producers. An extension of this study is suggested with the purpose of investigating other technological aspects aiming at the optimization of processes of fabrication and better quality of the beverage.

Keywords: "cachaça", chemical composition, quality, distilled.

\section{1 - INTRODUÇÃo}

O setor do agronegócio tem grande importância na geração de divisas para o País. Segundo o SEBRAE (29), o agronegócio da cachaça mais que triplicou entre 1970 e 1999, partindo de uma produção de 418 milhões de litros para cerca de 1,5 bilhões de litros anuais. As exportações de cachaça brasileira passaram de US\$ 7,3 milhões, em 1999, para US\$ 8,7 milhões, no ano de 2001. Conforme dados sobre a produção nacional, atualmente, existem mais de cinco mil marcas registradas, que exportam um volume superior a 20 milhões de litros ano para o exterior [17]. Esse aumento na produção associado ao incremento da exportação elevou a cachaça, de líquido "marginal", ao posto de bebida nobre, símbolo nacional e terceiro destilado mais consumido no mundo [13].

\footnotetext{
${ }^{1}$ Recebido para publicação em 21/9/2005. Aceito para publicação em 20/10/2006 (001612)

${ }^{2}$ Universidade Regional do Noroeste do Rio Grande do Sul (UNIJUI), Rua do Comércio, 3000, Bairro Universitário, Ijuí (RS), Brasil,

E-mail:sjbogusz@yahoo.com.br

${ }^{3}$ Curso de Farmácia, UNIJUI,

${ }^{4}$ Coordenadoria de Gestão e Desenvolvimento Tecnológico (CGDT), UNIJUI

* A quem a correspondência deve ser enviada
}

Segundo a Legislação Brasileira, Instrução Normativa número 13 de 29/06/2005, que fixa os padrões de identidade e qualidade para aguardente de cana e cachaça, o termo aguardente de cana refere-se a:

[...] bebida com graduação alcoólica de 38 a 54\% em volume a $20^{\circ} \mathrm{C}$, obtida do destilado alcoólico simples de cana-de-açúcar ou pela destilação do mosto fermentado do caldo de cana-de-açúcar, podendo ser adicionada de açúcares em até 6 g.L.expressos em sacarose.

Enquanto que, pela mesma Instrução Normativa, cachaça refere-se a:

[...] denominação típica e exclusiva da aguardente de cana produzida no Brasil, com graduação alcoólica de 38 a $48 \%$ em volume a $20^{\circ} \mathrm{C}$, obtida pela destilação do mosto fermentado do caldo de cana-de-açúcar com características sensoriais peculiares, podendo ser adicionada de açúcares em até 6 g. $\mathrm{L}^{-1}$, expressos em sacarose [5].

O Decreto número 4062 de 21/12/2001 e a Lei da Propriedade Industrial número 9279 de 14/05/1996 definem as expressões "Cachaça", "Brasil" e "Cachaça do Brasil" como produto de qualidade única tendo em vista as suas 
características naturais e as indicações geográficas brasileiras $[5,7,13]$.

O processo produtivo da cachaça pode ser resumido conforme os seguintes estágios: preparação da matéria prima (corte, separação das folhagens, transporte e armazenamento), seguida da extração do caldo, para, logo após, ocorrer a fermentação. O resultado dessa fermentação é levado à destilação, do qual, por meio de uma coluna de destilação ou alambique, se extrai a cachaça. Esta pode ainda ser envelhecida em barril de madeira, antes de ser engarrafada e distribuída para a comercialização [18].

Durante a fermentação alcoólica, ocorre o desdobramento dos açúcares do caldo de cana com formação de dois produtos principais: álcool etílico e dióxido de carbono. Além desses, há, normalmente a formação de pequenas quantidades de outros componentes, os quais recebem a denominação de produtos secundários da fermentação alcoólica, tais como ácidos carboxílicos, metanol, ésteres, aldeídos e álcoois superiores [8].

A Região Noroeste do Rio Grande do Sul possui uma significativa quantidade de pequenos produtores de cachaça. Estes possuem nesta atividade agroindustrial uma forma de geração de renda, divisas e empregos. Entretanto, é de conhecimento comum que muitos leigos se encontram à frente das unidades produtoras executando o processo, muitas vezes, de maneira empírica e rudimentar, baseados no senso comum ou em informações que passam de pai para filho. Tais fatos, associados à importância econômica e à expansão do setor, levaram à necessidade de se conhecer a composição química da bebida produzida na região, a fim de confrontar os resultados obtidos com os limites estabelecidos pela Legislação e fornecer dados para futuras ações de capacitação dos produtores quanto à importância da qualidade do produto.

Os requisitos de qualidade e composição química para cachaça no Brasil, fixados pela Instrução Normativa número 13 de 29/06/2005 são: somatório de componentes secundários "não álcool" (acidez volátil em ácido acético), aldeídos (em acetaldeído), ésteres totais (em acetato de eltila), álcoois superiores (soma do álcool n-propílico, isobutílico, e isoamílico) e furfural + hidroximetilfurfural não inferior a $200 \mathrm{mg} .100 \mathrm{~mL}^{-1}$ de álcool anidro e não superior a $650 \mathrm{mg} .100 \mathrm{~mL}^{-1}$ de álcool anidro. Observando os seguintes limites máximos: $150 \mathrm{mg} .100 \mathrm{~mL}^{-1}$ de álcool anidro para acidez volátil (expressa em ácido acético), $200 \mathrm{mg} .100 \mathrm{~mL}^{-1}$ de álcool anidro de ésteres (expressos em acetato de etila), $30 \mathrm{mg} .100 \mathrm{~mL}^{-1}$ de álcool anidro de aldeídos totais (expressos em aldeído acético), $5 \mathrm{mg} .100 \mathrm{~mL}^{-1} \mathrm{de}$ álcool anidro de furfural + hidroximetilfurfural e $360 \mathrm{mg}$ de álcoois superiores por $100 \mathrm{~mL}$ de álcool anidro (expressos pela soma dos álcoois n-propílíco, isobutílico e isoamílico), além de uma quantidade não superior a 20,0 mg de metanol por $100 \mathrm{~mL}$ de álcool anidro [6].

Com base no exposto, objetivou-se conhecer a composição química da cachaça produzida na Região Noroeste do Estado do Rio Grande do Sul.

\section{2 - MATERIAL E MÉTODOS}

No período de junho a agosto de 2004 , foram coletadas vinte e sete amostras de cachaça, provenientes da Região Noroeste do Rio Grande do Sul: Microrregião Ijuí (municípios de Ajuricaba, Augusto Pestana, Condor, Ijuí, Panambi e Santo Augusto), Microrregião Três Passos (Bom Progresso, Campo Novo, Horizontina, Sarandi e Três Passos), Microrregião Santa Rosa (Catuípe, Giruá, Santa Rosa e Santo Ângelo) e Microrregião Cruz Alta (Colorado, Cruz Alta e Jóia). Todas as amostras foram adquiridas no comércio local dos referidos municípios. Após a coleta, as amostras foram devidamente identificadas e armazenadas até o momento das avaliações.

O grau alcoólico real foi determinado por método densimétrico. A acidez volátil foi determinada por arraste de vapor em destilador Cazenave-Ferré, sendo o extrato obtido titulado e os resultados expressos em miligramas de ácido acético por $100 \mathrm{~mL}$ de álcool anidro. As avaliações do teor de aldeídos, ésteres, álcoois superiores e metanol foram realizadas por cromatografia gasosa, utilizando-se cromatógrafo a gás Varian 3400 acoplado a um detector de ionização de chama (FID) a uma temperatura de $250{ }^{\circ} \mathrm{C}$. A coluna foi do tipo Mega Bore modelo DBWAX de $30 \mathrm{~m}$ de comprimento, 0,53 $\mathrm{mm}$ de diâmetro interno e $1 \mu \mathrm{m}$ de espessura. A temperatura inicial do forno foi de $50{ }^{\circ} \mathrm{C}$, mantida por três minutos, com um aumento de $8{ }^{\circ} \mathrm{C}$ por minuto até $100{ }^{\circ} \mathrm{C}$, na qual permanecia por $0,75 \mathrm{~min}$. Para a análise estatística aplicaram-se os testes de ANOVA e Tukey, utilizando-se o software SPSS versão 7.5.

\section{3 - RESULTADOS E DISCUSSÃO}

Na Tabela 1, podem-se observar os resultados das avaliações quanto aos valores médios, desvio padrão e intervalo de concentração do grau alcoólico, acidez volátil, álcool npropílíco, álcool isobutílico, álcool isoamílico, somatório de álcoois superiores, aldeídos, ésteres e metanol, nas amostras de cachaça. Quanto aos valores médios do teor alcoólico, as amostras provenientes da microrregião Ijuí apresentaram valores de $42,64 \%$ em volume a $20{ }^{\circ} \mathrm{C}$, enquanto que as oriundas das microrregiões Três Passos, Santa Rosa e Cruz Alta apresentaram teores alcoólicos de 38,90, 39,60 e $38,23 \%$ em volume a $20{ }^{\circ} \mathrm{C}$, respectivamente, valores que estão dentro do que estabelece a Legislação [06], porém o intervalo de concentração revelou a existência de amostras com teor alcoólico abaixo do que preconiza a Lei.Valores de teor alcoólico para bebidas destiladas fora dos limites legais, independente do local de origem das amostras, indicam falta de conhecimento tecnológico de produção no que diz respeito a técnicas de destilação e/ou no procedimento de padronização do produto. Em um estudo similar, DALLA COSTA (16), investigando o perfil analítico de aguardentes da região central do Rio Grande do Sul, encontrou valores mínimos e máximos de teor alcoólico de 38,00 a 55,98\% em volume a $20{ }^{\circ} \mathrm{C}$. Enquanto que MIRANDA et al. (26), investigando o grau alcoólico e níveis de metanol em aguardentes no Estado da Bahia, provenientes das cidades de Santo Amaro e Salvador, encontraram, nas amostras artesanais 
TABELA 1 - Valores médios \pm desvio padrão e intervalo de concentração do grau alcoólico, acidez volátil, álcoois n-propílico, isobutílico e isoamílico, somatório de álcoois superiores, aldeídos, ésteres e metanol, em amostras de cachaça pertencentes a quatro microrregiões integrantes da Região Noroeste do Rio Grande do Sul, Brasil.

\begin{tabular}{|c|c|c|c|c|c|c|c|c|}
\hline \multirow[t]{2}{*}{ Componente } & \multicolumn{8}{|c|}{ Microrregião } \\
\hline & Média \pm DP & $\begin{array}{c}\text { Intervalo de } \\
\text { concentração }\end{array}$ & Média \pm DP & $\begin{array}{l}\text { Intervalo de } \\
\text { concentração }\end{array}$ & Média \pm DP & $\begin{array}{c}\text { Intervalo de } \\
\text { concentração }\end{array}$ & Média \pm DP & $\begin{array}{l}\text { Intervalo de } \\
\text { concentração }\end{array}$ \\
\hline $\begin{array}{l}\text { Grau } \\
\text { alcoólico } \\
\% \text { v/v } 20{ }^{\circ} \mathrm{C}\end{array}$ & $42,64 \pm 3,22$ & $37,3-47,7$ & $38,90 \pm 2,69$ & $35,70-43,40$ & $39,6 \pm 3,42$ & $35,60-43,20$ & $38,23 \pm 6,20$ & $31,10-45,70$ \\
\hline $\begin{array}{l}\text { Acidez } \\
\text { Volátil (mg } \\
\mathrm{CHCOOH} \\
100 \mathrm{~mL}^{-1} \\
\text { EtOH) }\end{array}$ & $40,13 \pm 5,39$ & $5,04-130,5$ & $29,91 \pm 13,31$ & $15-48,60$ & $64,20 \pm 65,60$ & $20,40-180,00$ & $66,70 \pm 81,21$ & $10,20-185,80$ \\
\hline $\begin{array}{l}\text { Álcool n-ropí- } \\
\text { lico (mg } 100 \\
\left.\mathrm{~mL}^{-1} \mathrm{EtOH}\right)\end{array}$ & $21,61^{\mathrm{A}} \pm 4,18$ & $15,73-29,42$ & $18,78^{A} \pm 3,67$ & $13,69-24,42$ & $25,12^{A} \pm 13,14$ & $11,45-40,18$ & $47,27^{\mathrm{B}} \pm 22,43$ & $32,47-80,46$ \\
\hline $\begin{array}{l}\text { Álcool Isobu- } \\
\text { tílico (mg } 100 \\
\left.\mathrm{~mL}^{-1} \mathrm{EtOH}\right)\end{array}$ & $49,90 \pm 12,15$ & $35,60-74,00$ & $83,93 \pm 98,18$ & $37,39-305,57$ & $43,40 \pm 18,68$ & $30,16-75,41$ & $48,00 \pm 20,68$ & $32,27-77,53$ \\
\hline $\begin{array}{l}\sum \text { Álcoois } \\
\text { superiores } \\
\left(\mathrm{mg} 100 \mathrm{~mL}^{-1}\right. \\
\text { EtOH) }\end{array}$ & $202,47 \pm 50,86$ & $145,19-317,21$ & $244,76 \pm 102,73$ & $153,31-455,98$ & $172,82 \pm 61,77$ & $123,42-272,29$ & $209,22 \pm 68,16$ & $153,74-305,06$ \\
\hline 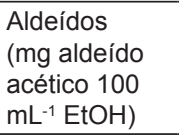 & $5,72^{a} \pm 3,10$ & $1,39-11,83$ & $8,83^{a} \pm 4,02$ & $3,66-13,91$ & $16,48^{\mathrm{b}} \pm 7,37$ & $5,49-25,63$ & $8,41^{a} \pm 2,71$ & $4,93-11,38$ \\
\hline $\begin{array}{l}\text { Ésteres }(\mathrm{mg} \\
\text { acetato de } \\
\text { etila } 100 \mathrm{~mL}^{-1} \\
\text { EtOH) }\end{array}$ & $30,53 \pm 16,89$ & $12,33-66,62$ & $21,23 \pm 13,12$ & $6,63-42,79$ & $44,18 \pm 12,16$ & $28,48-61,34$ & $40,02 \pm 29,89$ & $11,60-67,62$ \\
\hline
\end{tabular}

Os resultados são apresentados com média das amostras analisadas. ND = não detectado. DP = desvio padrão; Valores na mesma linha que mostram letras maiúsculas diferentes indicam diferenças altamente significativas ( $\mathrm{p}<0,01$ ); Valores na mesma linha que mostram letras minúsculas diferentes indicam diferenças significativas ( $<<0,05$ ).

analisadas, teores alcoólicos de 37,66 a 38,60\% em volume a $20{ }^{\circ} \mathrm{C}$. Ao passo que AZEVEDO et al. (2), determinando compostos secundários em cachaças produzidas no Estado de Minas Gerais, encontraram valores de teor alcoólico entre 34 a $50 \%$ em volume a $20{ }^{\circ} \mathrm{C}$. Embora tenham sido encontrados diferentes valores de teor alcoólico para as amostras investigadas na presente pesquisa, não foram observadas diferenças estatísticas significativas para este parâmetro.

Os valores médios de acidez volátil encontrados situaram-se abaixo do limite máximo de $150 \mathrm{mg}$ de ácido acético por $100 \mathrm{~mL}$ de álcool anidro, conforme estabelece a Legislação. Os maiores valores médios de acidez volátil foram verificados nas amostras provenientes da microrregião Cruz Alta, enquanto que os menores valores médios foram verificados nas amostras oriundas da microrregião Três Passos (66,70 e 29,91 mg de ácido acético por $100 \mathrm{~mL}$ de álcool anidro, respectivamente). Entretanto, os intervalos de concentração para este parâmetro revelaram que as amostras das microrregiões Cruz Alta e Santa Rosa apre- sentaram acidez volátil acima do máximo estabelecido em Lei (185,80 e 180,00 mg de ácido acético/100 mL de álcool anidro, respectivamente). Tais dados são um indicativo de possíveis problemas relativos a características sensoriais nestas amostras, uma vez que a acidez volátil é um importante parâmetro correlacionado às características sensoriais de bebidas alcoólicas destiladas [4]. Estes dados revelam falta de conhecimentos técnicos por parte dos produtores destas amostras, pois, segundo CARDOSO (9), os teores de acidez volátil da cachaça dependem de fatores como o adequado controle do tempo e da temperatura durante o processo fermentativo, tipo de levedura utilizada, manejo do mosto e, principalmente, higiene no processo de fabricação.

Quanto aos teores de álcool n-propílíco, verificou-se que as amostras coletadas na microrregião Cruz Alta apresentaram os maiores níveis médios para este composto (47,27 mg. $100 \mathrm{~mL}^{-1}$ de álcool anidro), seguidas das amostras das microrregiões Santa Rosa (25,12 mg. $100 \mathrm{~mL}^{-1}$ de álcool anidro), Ijuí (21,61 mg.100 mL $\mathrm{m}^{-1}$ de álcool anidro) e Três Passos (18,78 mg.100 mL de álcool anidro). As amostras da 
microrregião Cruz Alta apresentaram diferenças altamente significativas ( $\mathrm{p}<0,01$ ) quanto aos níveis de álcool n-propílíco, se comparadas às demais, o que indica carência de conhecimentos técnicos quanto ao processo fermentativo e de obtenção do destilado alcoólico. Segundo YOKOYA (33), o controle do nível de álcool n-propílíco na cachaça é importante na operação de fermentação. BOZA \& HORII et al. (4) demonstraram que, juntamente com a acidez, os teores de álcool n-propílíco influenciam na qualidade sensorial da cachaça. O mesmo foi relatado por ALMEIDA \& BARRETO (1), quando observaram maiores teores de álcool n-propílíco em aguardente de qualidade sensorial inferior. GIUDICI et al. (19) verificaram que a produção de álcool n-propílíco está relacionada ao metabolismo de metionina e de treonina e estes são reguladores das rotas metabólicas de compostos sulfurados. CLETO (12) verificou que a adição de fubá de milho no processo fermentativo, uma prática comum na etapa de fermentação do mosto de cana de açúcar, reduz a concentração de álcool n-propílíco e diminui a acidez total do destilado melhorando sua qualidade. Este autor conclui também que o milho canjica, matéria-prima para a produção de fubá, contém aproximadamente 0,39\% de treonina e o aumento deste aminoácido na fermentação pode influenciar nos processos de regulação da rota biossintética de álcool n-propílíco.

Os teores de álcool isobutílico e álcool isoamílico foram maiores nas amostras da microrregião Três Passos (83,93 e 142,05 mg. $100 \mathrm{~mL}^{-1}$ de álcool anidro, respectivamente), enquanto que os menores níveis médios destes mesmos compostos foram verificados nas amostras da microrregião Santa Rosa (43,40 e 104,30 mg. $100 \mathrm{~mL}^{-1}$ álcool anidro, respectivamente).

Os valores médios do somatório de álcoois superiores (álcoois com mais de dois átomos de carbono) para as amostras das quatro microrregiões não excederam o limite máximo de $360 \mathrm{mg} .100 \mathrm{~mL}^{-1}$ de álcool anidro estabelecido pela Legislação [06]. Não foram verificadas diferenças estatísticas significativas quanto aos níveis médios do somatório de álcoois superiores. Segundo YOKOYA (33), a formação de álcoois superiores é maior quando o fermento apresenta atividade biológica fraca, ocasionando demora no processo fermentativo. Teores elevados de álcoois superiores totais têm origem nas condições em que se realizou o processo fermentativo, pois a presença em excesso de borras ao longo da fermentação alcoólica provoca um aumento de até $50 \%$ no teor de álcoois superiores, com exceção do álcool n-propílíco que depende de outros fatores, como os descritos anteriormente [16]. Outro fator relacionado com o teor destes compostos é um adequado processo de destilação, com a separação das frações denominadas de cabeça, coração e cauda. De acordo com CHAVES (11), em geral, denomina-se cachaça de cabeça os $10 \%$ iniciais do processo de destilação e cachaça de cauda os $10 \%$ finais, enquanto que a fração coração constitui os 80\% intermediários a estas, constituindo a fração da "cachaça de boa qualidade". MAIA (23) verificou que os álcoois superiores, por serem de maior peso molecular, incorporam-se principalmente ao chamado destilado de cauda, ou seja, à última porção da destilação, caracterizada por apresentar grau alcoólico médio abaixo de $10 \%$ em volume a $20{ }^{\circ} \mathrm{C}$. Porém muitos produtores não possuem tais conhecimentos, efetuando a interrupção da destilação ou o chamado corte de forma muito variável, havendo casos em que este é muito baixo, chegando a menos que $2 \%$ em volume a $20^{\circ} \mathrm{C}$, o que pode ocasionar um aumento de álcoois superiores na cachaça. Além disso, CARDOSO et al. (10), verificando a influência do material do destilador na composição química das aguardentes, comprovaram que o teor de álcoois superiores diminui na seguinte ordem, dependendo da composição do material empregado na destilação: porcelana $>$ aço inox $>$ cobre $>$ alumínio. Os intervalos de concentração para o somatório de álcoois superiores revelaram que apenas para as amostras oriundas da microrregião Três Passos encontraram-se níveis destes compostos acima do máximo estabelecido por Lei (455,98 mg. $100 \mathrm{~mL}^{-1}$ de álcool anidro).

As amostras da microrregião Santa Rosa foram as que apresentaram os maiores níveis de aldeídos, se comparadas às demais (16,48 mg aldeído acético por $100 \mathrm{~mL}$ de álcool anidro), enquanto que os menores níveis foram observados nas amostras da microrregião Ijuí (5,72 mg aldeído acético por $100 \mathrm{~mL}$ de álcool anidro). Embora nenhuma das amostras analisadas indicasse teores de acetaldeído superiores aos $200 \mathrm{mg} .100 \mathrm{~mL}^{-1}$ de álcool anidro, as procedentes da microrregião Santa Rosa apresentaram diferenças estatisticamente significativas nos níveis médios deste composto se comparada às demais. VARGAS \& GLORIA (31), NASCIMENTO (27) e BOZA \& HORII (4), ao investigarem os teores de acetaldeído em aguardente, não encontraram amostras com teores deste composto acima dos limites legais. Os aldeídos, embora sejam constituintes normais em vinhos e destilados, podem produzir modificações indesejáveis sobre o aroma deles [15]. Aldeídos formados com até oito átomos de carbono têm aromas penetrantes, geralmente enjoativos, sendo indesejáveis em bebidas. Quando presentes no produto final, em excesso, podem provocar náuseas, vômitos, cefaléia, decréscimo da pressão cardíaca e taquicardia [21].

Quanto aos valores médios de ésteres, as amostras da microrregião Santa Rosa revelaram os maiores níveis deste composto, apresentando 44,18 mg. $100 \mathrm{~mL}^{-1}$ de álcool anidro, seguidas pelas amostras das microrregiões Cruz Alta, Ijuí e Três passos $\left(40,02,30,53\right.$ e 21,23 mg. $100 \mathrm{~mL}^{-1} \mathrm{de}$ álcool anidro, respectivamente). Segundo BORZANI et al. apud MAIA (23), o acetato de etila corresponde a cerca de $80 \%$ do conteúdo total de ésteres da aguardente. Este éster é característico da fração cabeça do destilado e participa de forma negativa sobre sua qualidade final [22]. Por isso, teores baixos destes compostos são sempre desejáveis em bebidas destiladas. Por ser característico da fração cabeça, o acetato de etila, pode ter seu conteúdo controlado e ajustado pela técnica adequada de destilação, objetivando o recolhimento da fração ideal do destilado de coração. Além disso, o uso de levedura e substrato ideais, bem como um adequado monitoramento do tempo de fermentação, auxilia no controle de altas quantidades de ésteres [24]. 
Nenhuma das amostras provenientes das quatro microrregiões apresentou níveis médios de ésteres acima do limite máximo permitido para este composto. Os ésteres, em geral, são formados durante a fermentação alcoólica graças às leveduras e bactérias [25], os ésteres dos ácidos graxos são formados pela ativação dos ácidos carboxílicos, pela descarboxilação oxidativa dos ácidos, pela síntese dos ácidos monocarboxílicos e seus intermediários de cadeia longa e pela álcoolise dos compostos da acetil-Coenzima-A [28]. A formação dos ésteres tem origem em fatores que fazem parte da composição do meio fermentativo, como por exemplo, os teores de aminoácidos, glicose e cátions [25], concentração de carbonos, suplemento nitrogenado, utilização dos micronutrientes e nível de insaturação dos ácidos graxos presentes [30]. Além disso, fatores como a cultivar de cana-de-açúcar empregada, as linhagens de leveduras, a temperatura de fermentação, a concentração de $\mathrm{CO}_{2}$, a oxigenação do meio [20], a turbidez, o teor de dióxido de enxofre e o $\mathrm{pH}$ do meio [25] podem influenciar na sua formação.

Os teores médios de metanol encontrados nas amostras analisadas permaneceram abaixo do limite máximo estabelecido para este composto pela Legislação (20 mg.100 $\mathrm{mL}^{-1}$ de álcool anidro). Estes dados diferem dos resultados descritos por MIRANDA et al. (26) que encontraram níveis de metanol acima do máximo permitido por Lei em cinco amostras de aguardentes provenientes do Estado da Bahia. Dados semelhantes foram encontrados por ZENEBON et al. (34) que, pesquisando os níveis de metanol em amostras de bebidas alcoólicas provenientes do Estado de São Paulo, encontraram 8 amostras com metanol excedendo os limites legais. Resultados diferentes foram encontrados em pesquisas mais recentes por BOZA \& HORII (4) e BOSCOLO (3) que não encontraram metanol em níveis acima do permitido pela Legislação.

Os dados de baixos níveis de metanol encontrados na presente pesquisa são de relevância, principalmente, no que diz respeito à segurança toxicológica relativa a este composto. O metanol presente na cachaça origina-se a partir do metabolismo secundário das leveduras que fazem a fermentação das bebidas alcoólicas. Na cachaça, ele é formado principalmente quando não se tem o cuidado de separar, por filtragem, os fragmentos da cana-de-açúcar que se originam no momento da moagem ou passagem pela prensa. Estes fragmentos, também conhecidos como bagacilho, são ricos em substâncias pécticas que, por sua vez, possuem unidades metoxilas, as quais, quando liberadas pelas enzimas das leve duras fermentativas, dão origem ao metanol [12, 14]. O metanol no organismo é oxidado a ácido fórmico e posteriormente a $\mathrm{CO}_{2}$, provocando uma acidose grave, afetando o sistema respiratório, podendo levar ao coma e até mesmo à morte [19]. Sua ingestão, mesmo em quantidades reduzidas, em longos períodos de consumo, pode ocasionar cegueira e até mesmo a morte [32].

\section{4 - CONCLUSÓES}

As amostras avaliadas quanto aos valores médios de teor alcoólico, acidez, álcoois superiores, aldeídos, ésteres e metanol estão dentro do que estabelece a Legislação. Entretanto, os valores de intervalo de concentração para estes mesmos parâmetros revelaram amostras fora do estipulado por Lei, o que indica carência de informações técnicas de alguns produtores quanto às condições de fermentação alcoólica (local, levedura, higiene), ainda tempo e condições de armazenamento do vinho, antes da destilação e processo de destilação.

Destaca-se que este é o primeiro trabalho que apresenta dados sobre a composição química da cachaça produzida na Região Noroeste do Rio Grande do Sul. Sugere-se, portanto, a ampliação do presente estudo, com a finalidade de se investigar outros aspectos tecnológicos como a presença de contaminantes, processo biotecnológico, envelhecimento, e qualidade sensorial, tendo em vista a melhoria da qualidade da bebida.

\section{5 - REFERÊNCIAS BIBLIOGRÁFICAS}

[1] ALMEIDA, M. E. W.; BARRETO, H. H. C. Álcoois superiores em aguardente de cana por cromatografia em fase gasosa. Rev. Inst. Adolfo Lutz, São Paulo, v. 31 , p. 117-124, 1971.

[2] AZEVEDO, S. M. et al. Levantamento da contaminação por cobre nas aguardentes de cana-de-açúcar produzidas em Minas Gerais. Ciênc. agrotec. Lavras, v. 27, n. 3, p. 618-624, 2003.

[3] BOSCOLO, M. et al. Identification and dosage by HRGC of minor alcohols and esters in Brazilian sugar-cane spirit. J. Braz. Chem. Soc., São Paulo, v. 11, n. 1, 2000. Disponível em: <http://www.scielo.br/scielo. php?script $=$ sci_arttext $\&$ pid $=$ S0 103-50532000000 1 $00015 \& \operatorname{lng}=$ pt\&nrm $=$ iso $>$. Acesso em: 1/10/2004.

[4] BOZA, Y.; HORII, J. Influência da destilação sobre a composição e a qualidade sensorial da aguardente de cana de açúcar. Ciênc. Tecnol. Aliment. Campinas. v. 18, n. 4, p. 391-396, 1998

[5] BRASIL. Decreto no 4062, de 21 de dezembro de 2001. Define as expressões "cachaça", "Brasil" e "cachaça do Brasil" como indicações geográficas e dá outras providências. Diário Oficial da República Federativa do Brasil, Brasília, DF, 21 dez. 2001. Disponível em:<http://extranet.agricultura.gov. br/sislegis-consulta/consultarLegislacao.do?operacao $=$ visualizar $\& i$ $\mathrm{d}=1014>$. Acesso em 1/10/2004.

[6] BRASIL. Instrução Normativa n ${ }^{\circ} 13$ de 29 de junho de 2005. Aprova o Regulamento Técnico para Fixação dos Padrões de Identidade e Qualidade para Aguardente de Cana e para Cachaça. Diário Oficial da República Federativa do Brasil, Brasília, DF, 30 junho de 2005, Seção 1, p. 3.

[7] BRASIL. Lei $n^{\circ} 9279$ de 14 de Maio de 1996. Regula direitos e obrigações relativas à propriedade industrial. Diário Oficial da República Federativa do Brasil, Brasília, DF. Disponível em:<http://www.peduti.com. br/Legislacao/marcas-1.asp > . Acesso em 1/10/2004.

[8] CARDoso, M. G. Análises físico-químicas de aguardentes. In: _._. CARDOSO, M. G. Produção de Aguardente de Cana de Açúcar. 2a Edição, Lavras, UFLA, 2006. 
[9] CARDOSO, M. G. Análises físico-químicas de aguardentes. In: _. CARDOSO, M. G. Produção de Aguardente de Cana de Açúcar. $1^{\text {a }}$ Edição, Lavras, UFLA, 2001.

[10] CARDOSO, D. R. et al. Influence of the pot still material on the chemical composition of Brazilian sugar cane spirit: part II. Quím. Nova. São Paulo. v. 26. n. 2. 2003.

[11] CHAVES, J. B. P. Cachaça - produção artesanal de qualidade. $1^{\mathrm{a}}$ Edição. Viçosa, CPT/CEE - UFV, 1998. $78 \mathrm{p}$.

[12] CLETO, F. V. G. Influência da adição de ácido sulfúrico e de fubá de milho no processo fermentativo, rendimento e composição da aguardente de cana. Jaboticabal, 1997, 109 f. Dissertação (Mestrado). Faculdade de Ciências Agrárias e Veterinárias, Universidade Estadual Paulista "Júlio de Mesquita Filho". 1997.

[13] COPELlO, M. A mais brasileira das bebidas. Gazeta Mercantil, 30/11/2004. Caderno de Fim de semana.

[14] CRISPIM, J. E. Manual de Produção de Aguardente de Qualidade. Guaíba: Livraria e Editora Agropecuária, 2000, 336 p.

[15] CURVELO-GARCIA, A. S. Controle de qualidade dos vinhos. Química Enológica, Lisboa, Instituto da Vinha e do Vinho. 1988. 245 p.

[16] DALLA COSTA, E. R. Perfil analítico das aguardentes produzidas na regiáo central do Rio Grande do Sul, Santa Maria, 2002, 73 f. Dissertação (Mestrado). Programa de Pós-Graduação em Ciência e Tecnologia de Alimentos, Universidade Federal de Santa Maria (UFSM), 2002.

[17] FRANCO, C. De gole em gole a cachaça ganha mercado. O Estado de São Paulo, São Paulo, 24/02/2002. Caderno de Economia.

[18] FRANCO, D. W.; et al. O Envelhecimento de Aguardente de Cana-de-Açúcar em Tonéis de Madeira. Engarrafador Moderno, v. 4, n. 33, p. 30-33, 1994.

[19] GIUDICI, P. ; ZAMBONELLI, C.; KUNKEE, R. E. Increased production of n-propanol in wine by yeast strains having an impaired ability to form hydrogen sulfide. Am. J. Enol. Vitic. Davis. v. 44. n. 1. p. 17-21. 1993.

[20] KILLIAN, E. E. \& OUGH, C. S. Fermentation esters - formation and retention as affected by fermentation temperature. Am. J. Enol. Vitic. Davis. v. 30. n. 4, p. 301-305, 1979.

[21] LABIANCA, D. C. Acetaldehyde Syndrome and Alcoholism. Analyst, v. 47, p. 21, 1974.

[22] LAFON, J.; COUILLAUD, P. ; GAY - BELlE, F. Le Cognac as distillation. Paris, Editions J. B. Baillière. 1973. $285 \mathrm{p}$.

[23] MAIA, A. B. et al. Tecnologia para produção de aguardente de qualidade: Segundo curso de tecnologia para produção de aguardente de qualidade da Escola de
Engenharia da UFMG e Fundação Cristiano Otoni,1994. $65 \mathrm{p}$.

[24] MAIA, A. B. R. A. et al. Fermentação alcoólica semicontínua destinada a produção de aguardente. Bol. Soc. Bras. Ciênc. Tec. Alim. Campinas. v. 25. n. 1. p. 33-36.1991.

[25] MARIÑO, J. I. M. et al. Présence et évolution dês esters supérieurs, em fonction dês différents facteus, au cours de la fermentation alcoolique. Revue Française d'Oenologie, Paris, v. 23, n. 90, p. 41-48,1983.

[26] MIRANDA, M. P.; DANTAS, V. P.; DEL CORRAL, F. S. D. Grau alcoólico e níveis de metanol em aguardentes do comércio (no Estado da Bahia). Bol. Soc. Bras. Ciênc. Tec. Alim. Campinas. v. 26, n. 2, p. 104-107, 1992.

[27] NASCIMENTO, R. F. et al. Comparação dos métodos oficiais de análise e cromatográficos para a determinação dos teores de aldeídos e ácidos em bebidas alcoólicas. Ciênc. Tecnol. Aliment. Campinas. v. 18. n. 3, p. 350-355.1998.

[28] NYKAMEN, L \& NYKAMEN, I. Rum flavors of distilled beverages: Origin and development. Society of Chemical Industry/Ellis Harwood Limited. Chichester, UK p. 49-63, 1983.

[29] SEBRAE. Diagnóstico da cachaça de Minas Gerais. Belo Horizonte, 2001. Disponível em: <http://www. sebraemg.com.br/arquivos/programaseprojetos/agronegocios/Cachaca/Cacha\%c3\%a7a\%20MG.pdf> Acesso em: $1 / 10 / 2004$.

[30] SOLES, R. M.; OUGH, C. S.; KUNKEE, R.E. Ester concentration differences en wine fermented by various species and strains of yeasts. Am. J. Enol. Vitic. Davis, v. 33, n. 2, p. 94-98, 1992.

[31] VARGAS, E. A.; GLORIA, M. B. Gualidade da aguardente de cana (Saccharum officinarum, L.) produzida, comercializada e/ou engarrafada no Estado de Minas Gerais. Ciênc. Tecnol. Aliment, Campinas. v. 15. n. 1. p. 43-46, 1995.

[32] WINDHOLZ, M. The Merck Index. Rahway: Merck, 1976.

[33] YOKOYA, F. Fabricação de aguardente de cana. Campinas: Fundação Tropical de Pesquisas e Tecnologia "André Tosello", 1995, 87 p.

[34] ZENEBON, O.; BADOLATO, E. S. G.; NAGTO, L. A. F. Metanol - avaliação da ocorrência de intoxicações causadas pela ingestão de bebidas alcoólicas no estado de São Paulo. Bol. Soc. Bras. Ciênc. Tec. Alim. Campinas. v. 30 n. 1. p. 71-71. 1996.

\section{6 - AGRADECIMENTOS}

Ao Laboratório de Apoio Vegetal - LARV/MAPA, Porto Alegre, Rio Grande do Sul, pelo auxílio nas análises cromatográficas. E ao Laboratório de Estatística - LABEST - UNIJUI, pelo auxílio nas análises estatísticas. 